\title{
Long-term outcomes following functional endoscopic sinus surgery in Samter's triad
}

\author{
F OLIVIER $^{1}$, M GEORGE $^{1}$, D LEUBA $^{2}, \mathrm{P}_{\text {MONNIER }}{ }^{1}, \mathrm{~J} \mathrm{P} \mathrm{FRIEDRICH}^{2}$ \\ ${ }^{1}$ Otorhinolaryngology Service, Department of ENT, Head and Neck Surgery, Lausanne University Medical Centre \\ (CHUV), and ${ }^{2}$ Otorhinolaryngology Service, Head and Neck Surgery, Hospital of La Chaux-de-Fonds, \\ Switzerland
}

\begin{abstract}
Objective: This study aimed to assess the long-term outcome of functional endoscopic sinus surgery for Samter's triad patients using an objective visual analogue scale and nasal endoscopy.

Method: Using a retrospective database, 33 Samter's triad patients who underwent functional endoscopic sinus surgery were evaluated pre- and post-operatively between 1987 and 2007 in Hospital of La Chaux-de-Fonds, Switzerland.

Results: A total of 33 patients participated in the study, and the mean follow-up period was 11.6 years (range 1.2-20 years). Patients were divided into two groups based on visual analogue scale scores of the five parameters with the greatest difference in intensity of symptoms between the beginning and end of follow up. Group 1 included patients with a mean visual analogue scale score of 6 and below at the end of follow up and group 2 included patients with a mean visual analogue scale score of more than 6 . The only statistically significant difference noted between the two groups was the endonasal findings: stage III-IV polyposis was present in 1 out of 24 patients ( 4 per cent) in group 1 and in 5 out of 9 patients ( 56 per cent) in group 2.

Conclusion: The results of our study indicate that functional endoscopic sinus surgery helps stabilise disease progression. Stage III-IV polyposis had a significant adverse effect on long-term outcome.
\end{abstract}

Key words: Nasal Polyps; Aspirin Triad Disease; Endoscopic Surgical Procedure; Treatment Outcome

\section{Introduction}

Amino salicylic acid triad, first described by Widal in 1922 , is characterised by nasal polyposis, bronchial asthma and aspirin intolerance. It is also known as Samter's triad. ${ }^{1,2}$ The pathogenesis of this syndrome, originally described by Szczeklik et al., is thought to be due to increased activity of the leukotriene synthetase enzyme as a consequence of abnormal arachidonic acid pathway activity induced by aspirin and other nonsteroidal anti-inflammatory drugs. ${ }^{3}$ The late onset of enzyme dysfunction can result from age-related modifications. The leukotrienes LTC4, LTD4 and LTE4 induce mucosal oedema, influx of eosinophils, bronchospasm and increased mucus secretion into the airways. A study of 500 patients in Europe revealed the following sequence: persistent rhinitis, appearing at a mean age of $29.7 \pm 12.5$ years, and then asthma, aspirin intolerance and, finally, nasal polyposis. Concerning aspirin intolerance, only 6 per cent of patients show a positive family history. ${ }^{4}$

At first, endonasal surgery was considered harmful for asthma control in Samter's triad. Later, English and other surgeons reported good results in patients who were well stabilised during the peri-operative period. ${ }^{5}$ Various reports have shown a beneficial effect of surgery on the asthma component of the disease. ${ }^{6}$ A few reports have described overall encouraging functional results after functional endoscopic surgery (FESS) in Samter's triad. ${ }^{7-9}$ However, these all reported a mean follow up of less than four years. Vleming et al. showed the importance of correlating the subjective outcome with post-operative endoscopic findings. ${ }^{10}$ They also reported that rhinosinusitis with nasal polyps represents diseases of different origins and that the post-surgical outcome may not be comparable in patients with and without polyps. Currently, outcome after sinus surgery is assessed by correlating post-operative symptoms with endoscopic evaluation findings. ${ }^{11}$ Therefore, we aimed to evaluate long-term outcome using a visual analogue scale (VAS) combined with post-operative nasal endoscopy. It is possible that correlating these results could identify predictors of positive outcome in Samter's triad patients following FESS. 


\section{Materials and methods}

\section{Patients and evaluation}

Between 1987 and 2007, we identified 303 patients who had undergone endoscopic ethmoidectomy for diffuse nasal polyposis in the Otorhinolaryngology and Head and Neck surgical clinic, Hospital of La Chaux-de-Fonds, Switzerland. In this group, 39 Samter's triad patients were identified (13 per cent). Of these, 33 were included in this retrospective study to evaluate subjective general rhinological symptoms and nasal endoscopic status after a minimum follow up of one year; six patients were lost to follow up.

\section{Study design}

Pre-operative parameters were age at symptom onset, history of endonasal surgery, surgical complications, secondary infections, asthma evolution, use of topical corticosteroids, sequence of Samter's triad symptoms, history of smoking, allergies and a family history of Samter's triad. Each patient underwent a pre-operative computed tomography (CT) scan. A patient questionnaire based on a VAS ranging from 0 to 10 (where 0 indicates no discomfort and 10 indicates severe discomfort) rated functional impairment on global discomfort, physical activities, social and professional life, sleep, nasal obstruction, smell, anterior rhinorrhea, post-nasal drip, headache, sneezing, epiphora, and facial pain. The rating for each symptom included status before treatment at our hospital and current status during the last follow-up visit (range 1.2-20 years).

After functional endoscopic ethmoidectomy, all Samter's triad patients underwent meticulous endoscopic suction clearance for several weeks until normal epithelialisation was found in the sinus cavities. At the final visit, nasal endoscopy was also performed to quantify polyposis on a $0-4$ scale (Table I). For each patient, the residual functional impairment and endoscopic findings were analysed to identify any statistically significant associations with pre-operative characteristics.

\section{Statistical analysis}

Results were analysed using univariate analysis. The Mann-Whitney $U$ test was used for unpaired samples and Fischer's exact test for between-group

\begin{tabular}{|c|c|}
\hline \multicolumn{2}{|r|}{$\begin{array}{c}\text { TABLE I } \\
\text { POST-OPERATIVE POLYPOSIS STAGING BASED ON } \\
\text { NASAL ENDOSCOPY }\end{array}$} \\
\hline Stage & Description \\
\hline 0 & No polyp \\
\hline 1 & Polypoid mucosa \\
\hline 2 & $\begin{array}{l}\text { Polyp not extending below the inferior limit of the middle } \\
\text { turbinate }\end{array}$ \\
\hline 3 & $\begin{array}{l}\text { Polyp reaching below the middle turbinate but without } \\
\text { extension to the floor of the nasal fossa }\end{array}$ \\
\hline 4 & Polyp in contact with the floor of the nasal fossa \\
\hline
\end{tabular}

comparison. Statistical significance was set at a $p$ value of 0.05 .

\section{Results}

In all, 33 patients participated in the study ( 21 females and 12 males). The average age at onset was 31.9 years with a sequence of polyposis to asthma to amino salicylic acid intolerance occurring in 20 patients (61 per cent), and a sequence of asthma to polyposis to amino salicylic acid intolerance in 6 patients $(18$ per cent). All patients underwent allergy testing and 16 had polyallergies (48 per cent). Twenty-three patients (70 per cent) underwent complete allergy testing. After non-steroidal anti-inflammatory drugs, the most common allergens were pollens, dust mites, cat and dog hair, and antibiotics. There was a positive family history of related disease for eight patients $(24$ per cent), including asthma in four patients, polyposis in three and intolerance to aspirin in one. Pre-operative CT scans showed bilateral sinus opacities in 32 patients and unilateral disease in 1 patient.

The mean follow-up period was 11.6 years (range 1.2-20 years). Thirteen patients (39 per cent) had a history of prior surgery before the first intervention in our hospital, with a total of 49 surgical procedures (average of 3.8 operations per patient).

A total of 13 patients (39 per cent) needed revision surgery during the post-operative monitoring period after an average period of 6.5 years, with a total of 21 operations (1.3 operations per patient). Of these, six patients underwent revision surgery before the monitoring period. Two patients had complications in the series: one had temporary unilateral cortical blindness and one had maxillary nerve hypoesthesia.

Follow-up results with proportional distribution are shown in Table II. The four parameters with maximum functional impairment were hyposmia (VAS score 9.3, 6.1), nasal obstruction (VAS score 8.6, 4.2), sleep disturbance (VAS score 5.6, 3.1) and limited physical activity (VAS score 5.4, 2.7): the first value corresponds to clinical status before the intervention and the second value to residual discomfort at the end of follow up.

For global discomfort, the initial scale of moderate to severe discomfort was 6.5 on average, with a third of patients scoring between 8 and 10 and two-thirds scoring between 5 and 7. At the end of follow up, the average VAS score was 3.4, with 2 out of 33 (6 per cent) patients scoring between 8 and 10, and 9 out of 33 (27 per cent) patients scoring between 5 and 7 (with moderate to severe symptoms), resulting in a third of patients having mild to moderate symptoms at the end of monitoring period. The average superinfection rate during the early follow-up period was 1.7 per year, which later reduced to 0.9 per year.

Patients were divided into two groups based on VAS scores of the five parameters with the greatest difference in symptom intensity between the beginning and end of follow up (overall discomfort, physical activity, 


\section{TABLE II}

CHARACTERISTICS OF SAMTER'S TRIAD PATIENTS, STRATIFIED BY VAS SCORE

\begin{tabular}{llll}
\hline \multicolumn{1}{c}{ Characteristics } & Total & Group $1^{*}$ & Group $2^{\dagger}$ \\
\hline$n$ & 33 & 24 & 9 \\
Previous surgery $(n(\%))$ & $12(39)$ & 11 & 2 \\
Mean age of onset (y) & 31.90 & 31.67 & 32.44 \\
Female $(n(\%))$ & $21(64)$ & $15(62)$ & $7(78)$ \\
Mean follow up (y) & 11.6 & 10.7 & 13.8 \\
$\begin{array}{l}\text { Outcome }(n(\%)) \\
\text { - Polyallergy }\end{array}$ & $16(48)$ & $10(42)$ & $6(67)$ \\
- Endonasal stage III-IV & $6(18)$ & $1(4)$ & $5(56)$ \\
- Asthma reduction & $15(45)$ & $13(54)$ & $2(22)$ \\
Global discomfort score & & & \\
- Pre-op & 6.5 & 6.17 & 7.44 \\
- Post-op & 3.9 & 2.38 & 6.11 \\
$\begin{array}{l}\text { Physical activity score } \\
\text { - Pre-op }\end{array}$ & 5.39 & 5.33 & 5.56 \\
- Post-op & 2.73 & 1.75 & 5.33 \\
$\begin{array}{l}\text { Sleep disorder score } \\
\text { - Pre-op }\end{array}$ & 5.64 & 5.04 & 7.22 \\
- Post-op & 3.15 & 1.75 & 6.89 \\
Nasal obstruction score & & & \\
- Pre-op & 8.61 & 8.46 & 9.00 \\
- Post-op & 4.21 & 2.67 & 8.33 \\
$\begin{array}{l}\text { Hyposmia score } \\
\text { - Pre-op }\end{array}$ & & & \\
- Post-op & 9.33 & 9.25 & 9.56 \\
\hline
\end{tabular}

${ }^{*}$ VAS score $\leq 6 .{ }^{\dagger}$ VAS score $>6 . \mathrm{y}=$ years; pre-op $=$ pre-operative; post-op $=$ post-operative.

sleep, nasal obstruction and olfaction). Group 1 included patients with a mean VAS score of 6 or below at the end of follow up (indicating mild to moderate residual discomfort) and group 2 included patients with a mean VAS score of greater than 6 (indicating severe residual symptoms). Regarding these five criteria, the average residual discomfort for the whole group of 33 patients was evaluated as 3.9. There were 24 patients in group 1 and 9 patients in group 2 (Table II). The only significant difference noted between the two groups was in the endonasal findings: there was stage III-IV polyposis in 1 out of 24 patients (4 per cent) in group 1 and in 5 out of 9 patients (56 per cent) in group 2 . Female predominance was more pronounced in group $2(7: 2$, or 78 per cent) than in group 1 (15:7, or 62 per cent), reflecting the greater disease severity in women.

Although patients with polyallergies were seen more often in group 2 (6 out of 9; 67 per cent) than in group 1 (10 out of 24; 42 per cent), statistical significance was not reached. All patients with a positive family history belonged to group 1 . The mean follow up exceeded 10 years for both groups. A decreased incidence of asthma was observed in 13 out of 24 (54 per cent) patients in group 1, and in 2 out of 9 ( 22 per cent) patients in group 2. The mean age at symptom onset was the same for both groups. The number of secondary infections and revision surgery during the follow-up period was slightly higher in group 2 patients. However, the number of surgical procedures prior to treatment in our hospital and the total number of interventions were higher in group 1 patients.

\section{Discussion}

Of all the patients who undergo FESS, 10-20 per cent are reported to have aspirin triad disease. ${ }^{12,13}$ Longterm monitoring after endoscopic endonasal ethmoidectomy of Samter's triad shows significant residual symptomatology, with an average VAS score of 3.9. In our case series, patients with advanced polyposis who underwent FESS experienced a significant level of severe residual functional impairment (VAS score $>6$ ) at the end of follow up. Asthma symptoms remained stable or worsened in these patients. This finding may be explained by the increased inflammatory component of extensive polyposis, altered metabolism or reduced responsiveness to topical corticosteroids in these patients. Primary surgery should therefore be extensive to avoid the need for revision and, if necessary, to make it less risky because of the change to anatomical landmarks. Earlier reports did not find the rate of revision to be related to the surgical approach, although the endoscopic technique provided good results. ${ }^{8,11,12}$ Our results after long-term monitoring showed an average VAS score of 3.9. Hyposmia was the predominant residual symptom, followed by nasal obstruction. Family history of aspirin intolerance was seen in one patient in our group ( 3 per cent). Szczeklik et al. reported a positive family history of aspirin intolerance in 6 per cent of patients $(n=500)$, but this had less impact on disease progression compared with sexual predilection or the presence of atopy. ${ }^{4}$ However, in our series, poor prognosis was related to female sex and the presence of polyallergies, although the data were not statistically significant.

Amar et al. reported 18 Samter's triad patients and 22 patients in the control group to have chronic sinusitis (with or without asthma) after a mean follow up of 3.5 years. ${ }^{7}$ A history of prior surgery was noted in 11 out of the 18 Samter's triad patients and in 6 out of 22 patients in the control group. Revision surgery was needed for seven patients in the Samter's triad group and for two in the control group; the difference was statistically significant. The post-operative symptoms evaluated included pain, nasal obstruction, anosmia and rhinorrhea. The only significant difference in variables between groups was hypo-anosmia, which was present in 89 per cent of Samter's triad patients and 50 per cent of patients in the control group. McFadden et al. reported that in a group of 80 Samter's triad patients, bilateral sinus surgery by either a conservative or radical approach led to improved sinus symptoms and asthma in 85 per cent and 83 per cent of the patients, respectively, with an average follow-up of 3 years. ${ }^{8}$ The same group also reported that of 25 Samter's triad patients who underwent surgery for sinusitis with a mean follow up of 3.4 years, those who underwent radical surgery showed better symptom resolution, thus obviating the need for further surgery. ${ }^{9}$ Although these 
results seem very encouraging, the short follow up suggests that these are interim results, which may show a better outcome compared with our study that had a much longer follow up, and in which the first revision surgery occurred after 6.5 years.

Good asthma control in the peri-operative period prevented decompensation. In our patients, the dose of topical and systemic steroids was reduced or the disease was stabilised; these results were similar to those of Loehrl et al. and Nakamura et al. ${ }^{6,12}$ To evaluate the surgical treatment of sinusitis in Samter's triad, Nakamura et al. studied 22 patients who underwent sinus surgery. Subjective evaluation indicated that sinus surgery effectively treated asthma in 20 patients ( 90.9 per cent), with a mild to marked improvement. ${ }^{12}$ Good functional results were noted for nasal obstruction, rhinorrhea, hyposmia and asthma over a mean follow up of 4 years. Postoperative tests showed a significant improvement in pulmonary function over pre-operative tests. These patients also showed a significant reduction in the dose of systemic or topical steroids used after surgery.

Folia et al. reported their experience of treating 203 patients with endonasal endoscopic ethmoidectomy for nasal polyposis followed by intranasal corticotherapy. ${ }^{13}$ The patients' global satisfactory rate for this medico-surgical approach of treating the disease was 93.6 per cent. A positive correlation was found between severe olfactory disorders and the administration of oral corticosteroid therapy. No deterioration or improvement in asthma was seen in 92 per cent of these patients. In 65 patients with nasal polyposis refractory to intensive medical management, Dufour et al. noted a good improvement in patient quality of life following endoscopic sphenoethmoidecomy. ${ }^{14,15}$ They also noted a reduction in the required anti-asthmatic medication dosage for 24 out of 31 patients. Aspirin desensitisation was not observed in any patient in our series, although previous reports support a role for aspirin desensitisation treatment in aspirin-sensitive patients with rhinosinusitis and asthma. ${ }^{16,17}$ McMains and Kountakis reported that revision FESS has beneficial effects in Samter's triad patients. ${ }^{18}$ They also showed that aspirin desensitisation can decrease the likelihood of additional surgical intervention over a two-year period. A family history of aspirin triad disease was not found in our patients, although a hereditary aetiology has been reported. ${ }^{5,6}$

- Samter's triad is characterised by nasal polyposis, bronchial asthma and amino salicylic acid intolerance

- Long-term outcome after functional endoscopic sinus surgery was assessed using a visual analogue scale and nasal endoscopy

- Functional endoscopic sinus surgery helped stabilise the disease

- Stage III-IV polyposis had a significant adverse effect on long-term outcome
By acting as receptor antagonists, anti-leukotrienes have been reported to have a role in controlling postsurgical nasal polyposis. Effective control of asthma was seen and stabilisation of sinonasal polyposis was achieved in some patients by treatment with anti-leukotrienes. ${ }^{19-21}$ However, these drugs were not used in this study.

\section{Conclusion}

Long-term monitoring after endoscopic endonasal ethmoidectomy for Samter's triad showed an average VAS score of 3.9 (on a 0-10 scale). Our results therefore support a current management strategy of combination therapy comprising both medical and surgical therapy for Samter's triad. Our study findings indicate that endoscopic sinus surgery in Samter's triad patients helps stabilise the disease.

References

1 Widal F, Abrami P, Lermoyez J. First complete description of the aspirin idiosyncrasy-asthma-nasal polyposis syndrome. J Asthma 1987;24:297-300

2 Samter M, Beers RF Jr. Intolerance to aspirin. Clinical studies and consideration of its pathogenesis. Ann Intern Med 1968; 68: $975-83$

3 Szczeklik A, Gryglewski RJ, Czerniawska-Mysik G. Relationship of inhibition of prostaglandin biosynthesis by analgesics to asthma attacks in aspirin-sensitive patients. $\mathrm{Br}$ Med J 1975;11:67-9

4 Szczeklik A, Nizankowska E, Duplaga M. Natural history of aspirin-induced asthma. AIANE Investigators. European Network on Aspirin-Induced Asthma. Eur Respir J 2000;16: 432-6

5 English GM. Nasal polypectomy and sinus surgery in patients with asthma and aspirin idiosyncrasy. Laryngoscope 1986;96: 374-80

6 Loehrl T A, Ferre RM, Toohill RJ, Smith TL. Long-term asthma outcomes after endoscopic sinus surgery in aspirin triad patients. Am J Otolaryngol 2006;27:154-60

7 Amar YG, Frenkiel S, Sobol SE. Outcome analysis of endoscopic sinus surgery for chronic sinusitis in patients having Samter's triad. J Otolaryngol 2000;29:7-12

8 McFadden EA, Woodson BT, Flink JN, Toohill RJ. Surgical Treatment of Aspirin Triad Sinusitis. Am J Rhinol 1997;11: 263-70

9 McFadden EA, Kany RJ, Flink JN, Toohill RJ. Surgery for sinusitis and aspirin triad. Laryngoscope 1990;100:1043-6

10 Vleming M, Middeiweerd MJ, de Vries N. Good results of endoscopic paranasal sinus surgery for chronic or recurrent sinusitis and for nasal polyps [in Dutch]. Ned Tijdschr Geneeskd 1993 Jul 17;137:1453-6

11 Senior BA, Kennedy DW, Tanabodee J, Kroger H, Hassab M, Lanza DC. Long term impact of functional endoscopic sinus surgery on asthma. Otolaryngol Head Neck Surg 1999;121: $66-8$

12 Nakamura H, Kawasaki M, Higuchi Y, Takahashi S. Effects of sinus surgery on asthma in aspirin triad patients. Acta Otolaryngol 1999;119:592-8

13 Folia M, Lombard L, Verges S, Percodani J, Pessey JJ, Serrano El. Nasal polyposis: long term functional results in 203 patients treated by ethmoidectomy combined with intranasal corticotherapy [in French]. Rev Laryngol Otol Rhinol (Bord) 2003;124: $105-10$

14 Dufour X, Bedier A, Ferrie JC, Gohler C, Klossek JM. Diffuse nasal polyposis and diffuse co-morbidity. Study of 65 cases treated by endonasal endoscopic surgery [in French]. Ann Otolaryngol Chir Cervicofac 2004;121:292-7

15 Dufour X, Bedier A, Ferrie JC, Gohler C, Klossek JM. Diffuse nasal polyposis and endonasal endoscopic surgery: long-term results, a 65-case study. Laryngoscope 2004;114:1982-7

16 Stevenson DD, Hankammer MA, Mathison DA, Christiansen $\mathrm{SC}$, Simon RA. Aspirin desensitization treatment of aspirin- 
sensitive patients with rhinosinusitis-asthma: long-term outcomes. J Allergy Clin Immunol 1996;98:751-8

17 Pfaar O, Klimek L. Aspirin desensitization in aspirin intolerance: update on current standards and recent improvements. Curr Opin Allergy Clin Immunol 2006;6:161-6

18 McMains KC, Kountakis SE. Medical and surgical considerations in patients with Samter's triad. Am J Rhinol 2006;20:573-6

19 Parnes SM, Chuma AV. Acute effects of antileukotrienes on sinonasal polyposis and sinusitis. Ear Nose Throat J 2000;79:18-20

20 Di Renzo L, Artuso A, Cerqua N. Antileukotrienes in the prevention of postoperative recurrence of nasal polyposis in ASA syndrome. Acta Otorhinolaryngol Ital 2000;20:336-42

21 Fokkens WJ, Lund VJ, Mullol J, Bachert C, Alobid I, Baroody F et al. European position paper on Rhinosinusitis and nasal polyps. Rhinology 2012;50:1-12
Address for correspondence:

Dr M George,

Department of ENT, Head and Neck Surgery,

Lausanne University Medical Centre (CHUV),

Rue du Bugnon 46,

Lausanne,

Switzerland 1011

Fax: 41213142647

E-mail: roymercy@hotmail.com

Dr M George takes responsibility for the integrity of the content of the paper

Competing interests: None declared 